\title{
Effect of nitric oxide donors on uterine and sub-endometrial blood flow in patients with unexplained infertility: a randomized controlled trial
}

\author{
Mohamed A. Abdel Hafeez, Ashraf M. F. Kortam, Alaa M. A. Youssef, \\ Ahmed Reda*, Rehab M. Abdelrahman
}

Department of Obstetrics and Gynecology, Ain Shams University, Cairo, Egypt

Received: 01 May 2021

Accepted: 15 May 2021

\author{
*Correspondence: \\ Dr. Ahmed Reda, \\ E-mail: reda.ahmed@yandex.com
}

Copyright: (c) the author(s), publisher and licensee Medip Academy. This is an open-access article distributed under the terms of the Creative Commons Attribution Non-Commercial License, which permits unrestricted non-commercial use, distribution, and reproduction in any medium, provided the original work is properly cited.

\begin{abstract}
Background: Impaired sub-endometrial perfusion might reduce endometrial receptivity and possibly contribute to unexplained infertility. A favorable effect on sub-endometrial blood flow has been demonstrated with nitric oxide.

Methods: This randomized controlled trial evaluated the effect of nitroglycerine on uterine and sub-endometrial blood flow in women with unexplained infertility. Sixty women were randomized into 2 equal groups. The study group received $5 \mathrm{mg}$ nitroglycerine patch daily from day 2 of the cycle till the evaluation day and the control group received no treatment. Independent of the study arms, 30 parous women were included as the fertile group. Six to eight days after detecting luteinizing hormone surge, women were assessed for endometrial thickness, uterine artery blood flow with color Doppler and sub-endometrial blood flow with three-dimensional power Doppler.

Results: Compared to fertile women, cases with unexplained infertility (control group) had a significantly thinner endometrium, higher uterine artery Doppler indices and lower sub-endometrial blood flow. Women who received nitroglycerin showed a significant improvement in sub-endometrial blood flow while uterine artery blood flow did not show a significant difference; however, the values were also comparable to fertile women. In addition, no effect on endometrial thickness was found with nitroglycerin treatment. Nitroglycerin treatment side effects were headache, blurring of vision and hypotension. These adverse effects were not significant compared to controls.

Conclusions: In women with unexplained infertility, nitroglycerin significantly improved the sub-endometrial blood flow but did not affect the endometrial thickness.
\end{abstract}

Keywords: Unexplained, Infertility, Nitric oxide, Nitroglycerine, Doppler, Sub-endometrial

\section{INTRODUCTION}

The American society of reproductive medicine defined unexplained infertility as "inability of a couple to conceive for at least 12 months with unremarkable standard infertility evaluation". ${ }^{1}$ Around a third of women presenting with infertility are classified as unexplained as the natures of all underlying pathologies are still not fully determined and the currently available tools are still insufficient to detect all factors contributing to infertility. Implantation and receptivity of the endometrium has been a subject for research in these cases but still not fully elucidated. Implantation is supposed to take place during a 48 hours window 6-10 days after the luteinizing hormone surge. During this implantation window an increase in uterine blood flow was reported by several studies, and local angiogenesis was postulated to be a key event for implantation and gestation. ${ }^{2}$ Disturbance in this hemodynamics was implicated in reduction of endometrial receptivity resulting in infertility.

Defective endometrial receptivity represents one of the proposed etiologies and has been linked to unexplained infertility. ${ }^{3}$ Various strategies have been suggested to 
assess the endometrial receptivity. ${ }^{4}$ The current evaluation is based on several sonographic parameters ${ }^{5}$ with endometrial thickness being the most commonly studied parameter as a predictor for good endometrial receptivity. ${ }^{6}$ three dimensional power Doppler has been implicated in the workup for unexplained infertility as a tool for assessment of endometrial blood flow with a hypothesis that impaired sub-endometrial perfusion might reduce endometrial receptivity and possibly contribute to unexplained infertility. ${ }^{6-8}$

Nitric oxide has been demonstrated to play an essential role in reproduction and various adverse reproductive outcomes have been reported with defective nitric oxide synthesis. ${ }^{9-12}$ Previous studies have confirmed the role of nitric oxide in adjustment of uterine blood flow. A sixty percent reduction in uterine artery blood flow has been demonstrated with nitric oxide inhibitor, while a favorable effect on sub-endometrial blood flow has been reported with nitric oxide donors. ${ }^{13,14}$

This study evaluated the effect of nitroglycerine as a nitric oxide donor on uterine and sub-endometrial blood flow in women with unexplained infertility.

\section{METHODS}

This study was a randomized controlled trial which was carried out at Ain Shams university maternity hospital, Cairo, Egypt during the period between March 2017 and March 2020. The procedures used in this study adhere to the tenets of the declaration of Helsinki. Before the beginning of the study, and in accordance with local regulation, the protocol and all corresponding documents were declared for ethical approval by the Faculty of Medicine Ain Shams university research ethics committee. A written informed consent was signed by all participants before enrollment in the study after explaining the purpose and procedures of the study.

The study included 60 women with unexplained infertility who were divided into 2 equal groups ( 30 women each); the study (nitroglycerin) group which included women who received nitroglycerine transdermal patch and the control group which included women who received no treatment. Women were included if meeting the following criteria: age between 20-35 years, documented ovulation, patent fallopian tube either by hysterosalpingogram and/or laparoscopy, normal baseline hormonal profile and normal husband's semen analysis according to WHO 2010 criteria. The study excluded women with any identified cause for infertility and excluded women with any medical comorbidity, receiving ovulation induction or NSAIDs as well as women with any contraindications for nitric oxide.

Independent of the study arms, we added a third group (the fertile group) which included 30 fertile parous women. The aim of this group was to provide background information to confirm/ exclude impaired perfusion with unexplained infertility and to compare the effect of nitroglycerine, if any, to women with no fertility problems. For the fertile group we included women attending at family planning clinic with at least 1 prior term pregnancy and no history of infertility, subfertility or recurrent miscarriage. Recruitment and handling of the study population during the course of the study are shown in Figure 1.

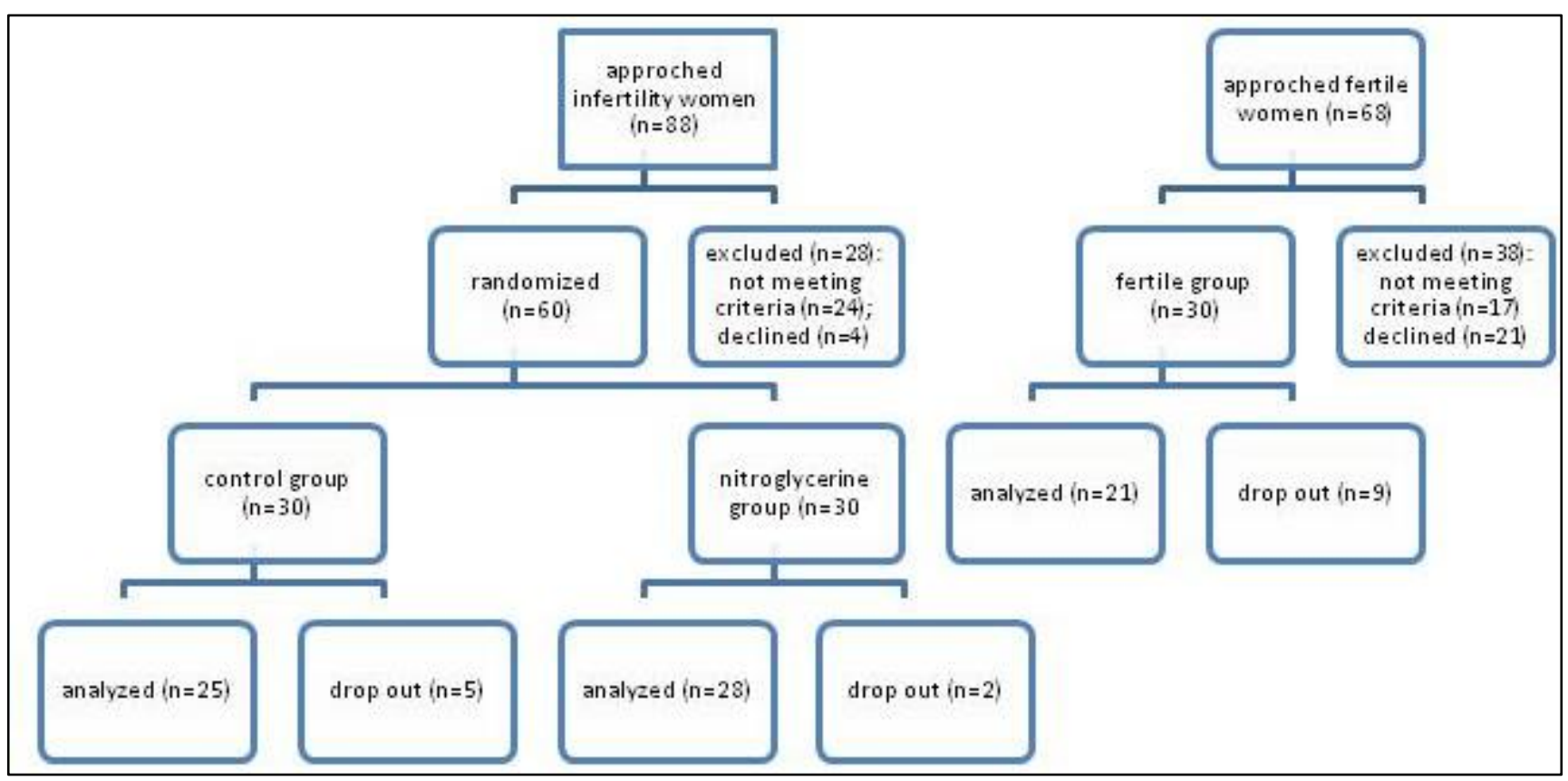

Figure 1: Flow diagram of the study. 
All included women were subjected to a blood sample on day 2 or 3 of the cycle to evaluate baseline hormonal profile then they were instructed to daily test a morning urine sample starting on cycle day 11 till detection of the luteinizing hormone surge using commercially available ovulation kits (Home Ovulation Kit, ACON Laboratories, Inc., San Diego, CA, USA). Then they were scheduled for a visit 6-8 days after detection of the luteinizing hormone surge; during this visit they were subjected to a transvaginal sonography to assess the endometrial thickness, uterine artery color Doppler and 3D power Doppler of sub-endometrial flow. Women in the study group received nitroglycerine (Nitroderm TTS®, Novartis, Egypt) $5 \mathrm{mg}$ patch as a source of nitric oxide and were instructed to wear a new patch every day for 12 hours beginning from $2^{\text {nd }}$ day of the cycle till the day of the ultrasound scan. Women in the control group as well as the fertile women received no treatment.

All ultrasound examinations were performed by a conventional 3D power Doppler ultrasound equipment Voluson E6 system (Voluson Expert, General Electric Medical Systems, Milwaukee, WI), with a four to nine $\mathrm{MHz}$ curved transducer. Ultrasound scans were performed with the women in the dorsal lithotomy position after they have completely emptied their bladders. Preliminary ultrasound was performed to assess uterus, ovaries and adnexa excluding any pathology. Then three-dimensional power Doppler identified the uterine artery and three similar consecutive waveforms were displayed and the resistance index and the pulsation index were measured and endometrial volume and indices of blood flow within the endometrium. The VOCAL (virtual organ computer aided analysis) software for the 3D power Doppler histogram analysis was then used to analyze with computer algorithms to form indices of blood flow and vascularization. Vascularization index was measured as the ratio of the number of color voxels to the total number of voxels and is expressed as a percentage of the endometrial volume, Flow index was recorded as the mean power Doppler signal intensity inside the endometrium, and vascularization flow index is a combination of vascularity and flow intensity.

\section{The study outcomes}

The primary outcome of this study was the effect of nitroglycerine on sub-endometrial blood flow measured by three-dimensional power Doppler. Secondary outcomes were: the effect of nitroglycerine on uterine blood flow measured by 2-dimensional color Doppler and endometrial thickness, side effects of treatment and pregnancy rate.

\section{Randomization, allocation and blinding (among unexplained infertility groups)}

In this study a computer-generated random list was used to allocate women with unexplained infertility to one of the study groups with 1:1 ratio. Allocation concealment was done through SNOSE (serially-numbered, opaque, sealed envelopes) method which enclosed a letter corresponding to the group assignment. After enrolment in the study, participants were assigned to a study identifying number given the next available number and envelopes were opened after the woman was enrolled. Blinding was deemed unnecessary in this study as all outcomes were objectively assessed. However, the sonographer who carried out the scans was blinded to the patient's assigned group.

\section{Sample size justification}

The study was planned to include 60 women with unexplained infertility divided into 2 equal groups. An effect size of 0.72 was expected with nitroglycerine treatment based on results from previous studies demonstrating improvement in the mean flow index ${ }^{14}$ and in the uterine artery pulsatility index. ${ }^{15}$ Sample size was calculated using $\mathrm{G}^{*}$ power program, using the following parameters: effect size $=0.72$, type- 1 error $(\alpha)=0.05$ and the power $(1-\beta)=0.8$ which resulted in a minimal sample size of 25 cases per group with 1:1 ratio. Assuming a 20\% dropout, 30 cases were included in each group. For the fertile group a sample size of 16 cases was required to detect an effect size of 0.91 with an $\alpha$ error $=0.05$ and the power $=0.8$ for a difference in the mean flow index between unexplained infertility and fertile cases based on results of a previous study. ${ }^{6}$ As control group was predetermined to include 30 women, the same size was planned for fertile group.

\section{Statistical methods}

Statistical package for social sciences (SPSS $®$ ) for Windows ${ }^{\circledR}$ version 24.0 (SPSS Inc, Chicago, IL, USA) was used. Data were analyzed on intention-to-treat basis. Parametric numerical data are presented as mean \pm standard deviation; whereas non-parametric numerical data are presented as median with interquartile range. Categorical data are presented as number and percentage. Difference between variables of two groups is measured using independent student's t-test (for numeric parametric variables), Mann-Whitney's U-test (for numeric nonparametric variables), and Chi-squared (for categorical variables). Three-group comparisons for numerical data were done using the ANOVA test for parametric data and using the Kruskal-Wallis test for non-parametric data. Post-hoc analysis was done using Tukey's and Dunn's post-hoc tests respectively. Categorical data were compared using Chi square test or Fisher exact test.

\section{RESULTS}

The baseline demographics, basal hormonal profile and clinical characteristics are shown in Table 1 and all variables were comparable between the three groups ( $p>0.05$ ) except parity which is expected to be significantly higher in the fertile group but the difference was not significant statistically between the nitroglycerin group and controls. 
Compared to fertile women, cases with unexplained infertility (the control group) had a thinner endometrium $(\mathrm{p}<0.001)$, higher pulsatility index $(\mathrm{p}=0.02)$ and resistance index $(\mathrm{p}=0.03)$ and lower vascularization index $(\mathrm{p}=0.006)$, flow index $(\mathrm{p}<0.001)$ and vascularization flow index $(\mathrm{p}<0.001)$. The difference regarding all these variables was significant statistically (Table 2).

Regarding the unexplained infertility cases, women who received nitroglycerin had a lower mean endometrial thickness than the control group, but the difference was not statistically significant $(\mathrm{p}=0.2)$. The difference in the uterine artery Doppler study was also not significant for both the mean pulsatility index $(\mathrm{p}=0.63)$ and resistance index $(p=0.23)$. A significant higher sub-endometrial blood flow was found among nitroglycerine treated women compared to controls with significantly higher vascularization index $(p<0.001)$, flow index $(p<0.001)$ and vascularization flow index $(\mathrm{p}<0.001)$.

Table 1: Baseline demographics and clinical characteristics of the study population.

\begin{tabular}{|llll|}
\hline Variables & Nitroglycerin group & Control group & Fertile group \\
\hline Age (years) & $28.4 \pm 3.7$ & $28.9 \pm 3.4$ & $28.0 \pm 3.1$ \\
\hline Body mass index $\left(\mathbf{k g} / \mathbf{m}^{\mathbf{2}}\right)$ & $26.2 \pm 3.1$ & $25.4 \pm 3.2$ & $26.2 \pm 4.1$ \\
\hline Parity & $1(0-2)$ & $1(0-2)$ & $2(1-3)$ \\
\hline Duration of infertility (years) & $3.6 \pm 1.3$ & $3.4 \pm 1.4$ & - \\
\hline Estradiol $(\mathbf{p g} / \mathbf{m L})$ & $25.8 \pm 5.9$ & $27.5 \pm 6.2$ & $25.7 \pm 6.2$ \\
\hline Follicle stimulating hormone (mIU/mL) & $6.8 \pm 1.5$ & $7.5 \pm 2.0$ & $7.5 \pm 1.9$ \\
\hline Luteinizing hormone (mIU/mL) & $4.3 \pm 1.3$ & $4.5 \pm 1.6$ & $4.6 \pm 1.5$ \\
\hline Thyroid stimulating hormone (mIU/mL) & $1.5 \pm 0.5$ & $1.3 \pm 0.6$ & $1.7 \pm 0.6$ \\
\hline Progesterone $(\mathbf{n g} / \mathbf{m L})$ & $11.6 \pm 3.3$ & $11.6 \pm 3.7$ & $11.6 \pm 3.3$ \\
\hline
\end{tabular}

Data are presented as mean \pm standard deviation except parity presented as median (interquartile range),

Table 2: Comparison between the three groups regarding the study outcomes.

\begin{tabular}{|c|c|c|c|c|c|c|c|}
\hline \multicolumn{2}{|l|}{ Variables } & $\begin{array}{l}\text { Nitroglycerin } \\
\text { group }\end{array}$ & $\begin{array}{l}\text { Control } \\
\text { group }\end{array}$ & $\begin{array}{l}\text { P value } \\
\text { (Nitroglycerin } \\
\text { vs control) }\end{array}$ & $\begin{array}{l}\text { Fertile } \\
\text { group }\end{array}$ & $\begin{array}{l}\text { P value } \\
\text { (Nitroglycerin } \\
\text { vs fertile) }\end{array}$ & $\begin{array}{l}\text { P value } \\
\text { (Controls vs } \\
\text { fertile) }\end{array}$ \\
\hline \multicolumn{2}{|c|}{$\begin{array}{l}\text { Endometrial } \\
\text { thickness (mm) }\end{array}$} & $7.94 \pm 1.14$ & $8.51 \pm 1.29$ & 0.20 & $11.14 \pm 1.07$ & $<0.001 *$ & $<0.001 *$ \\
\hline \multirow{2}{*}{$\begin{array}{l}\text { Uterine } \\
\text { artery 2D } \\
\text { Doppler }\end{array}$} & PI & $1.90 \pm 0.47$ & $2.01 \pm 0.31$ & 0.63 & $1.69 \pm 0.44$ & 0.19 & $0.02 *$ \\
\hline & RI & $0.81 \pm 0.22$ & $0.89 \pm 0.06$ & 0.23 & $0.76 \pm 0.21$ & 0.54 & $0.03 *$ \\
\hline \multirow{3}{*}{$\begin{array}{l}\text { Sub- } \\
\text { endometrial } \\
\text { 3D power } \\
\text { Doppler }\end{array}$} & VI & $2.36 \pm 0.66$ & $1.94 \pm 0.19$ & $0.001 *$ & $2.31 \pm 0.12$ & 0.92 & $0.006^{*}$ \\
\hline & FI & $35.29 \pm 5.93$ & $30.82 \pm 2.64$ & $<0.001 *$ & $36.69 \pm 3.09$ & 0.49 & $<0.001 *$ \\
\hline & VFI & $1.11 \pm 0.38$ & $0.79 \pm 0.29$ & $<0.001^{*}$ & $1.13 \pm 0.21$ & 0.97 & $<0.001^{*}$ \\
\hline
\end{tabular}

Data are presented as mean \pm standard deviation, ${ }^{*}=$ significant, $\mathrm{PI}=\mathrm{Pulsatility}$ index, $\mathrm{RI}=$ Resistance index, $\mathrm{VI}=\mathrm{Vascularization}$ index, $\mathrm{FI}=$ Flow index, VFI=Vascularization-flow index

The effect of nitroglycerine treatment was evaluated in comparison to fertile women. As shown in Table 2, the uterine artery Doppler pulsatility and resistance indices as well as the sub-endometrial 3D power Doppler vascularization index, flow index and vascularization flow index reached values comparable to fertile women ( $p>0.05)$ while the difference in endometrial thickness between both groups remained significant $(\mathrm{p}<0.001)$.

Nitroglycerin treatment side effects were headache in 2/30 $(6.67 \%)$ women (relative risk $=2.0,95 \%$ confidence interval $=0.19-20.9)$, blurring of vision in $4 / 30(13.3 \%)$ women (relative risk $=9.0,95 \%$ confidence interval $=0.50$ $160.2)$ and hypotension in $5 / 30(16.7 \%)$ women relative risk $=2.5,95 \%$ confidence interval $=0.53-11.9)$. These adverse effects were not significant compared to controls $(\mathrm{p}>0.05)$

Biochemical pregnancy was confirmed in 2/30 (6.67\%) women in the nitroglycerin group and in $1 / 30(3.33 \%)$ woman in the control group, this difference failed to prove the statistical significance but this outcome cannot be adequately concluded due to the very low rate in both groups.

\section{DISCUSSION}

Sub-endometrial blood flow has been previously investigated as a contributor to unexplained infertility but the reported results were conflicting..$^{7,16,17}$ It was also 
postulated that impaired uterine perfusion may play a possible role in the pathogenesis of unexplained infertility. ${ }^{18}$ Impaired uterine, sub-endometrial as well as ovarian perfusion has also been demonstrated in unexplained infertility cases by color Doppler study. ${ }^{19-21}$ Zebitay and colleagues agreed to this finding, in addition, they also stated that this difference does not exist among women with tubal factor infertility compared to fertile women; reserving this association to unexplained infertility. ${ }^{8}$ In this study, we found that unexplained infertility was associated with a significantly impaired uterine as well as sub-endometrial perfusion which was in agreement with previous reports. . $^{6,16,17}$

Schild et al suggested that sub-endometrial perfusion relates to fertility outcome more than uterine perfusion with the hypothesis that sub-endometrial blood flow may be masked by the larger proportion of uterine blood distributed to myometrium. ${ }^{22}$ This suggestion provided a possible explanation for the heterogenous evidence regarding the correlation between uterine artery Doppler flow values and pregnancy rate and suggesting a possible beneficial role of endometrial blood flow enhancement in the management of unexplained infertility.

This study investigated the potential role of nitric oxide donor to enhance endometrial blood flow in unexplained infertility. We found that nitroglycerine treatment significantly improved sub-endometrial blood flow to values similar to fertile women while the relatively underdeveloped endometrium showed no improvement and remained significantly thin compared to fertile women. We also found better uterine artery Doppler indices in the nitroglycerin-treated group although the difference did not reach significance; however, the indices were improved to values comparable to the fertile group. This observation probably reflects an inconsistent response rather than no response to nitroglycerin treatment as the $95 \%$ confidence interval of the mean values in the nitroglycerin-treated group spanned a large range of values overlapping with both lower interval of fertile group and higher interval of control unexplained infertility group.

To the authors' knowledge there are no reports investigating nitroglycerine in natural cycles as a potential management for cases with unexplained infertility although few studies have evaluated its role to improve pregnancy rate in women undergoing in vitro fertilization before embryo transfer. ${ }^{23,24}$ Furthermore, the existing evidence regarding the role of vasodilators in reproductive medicine is scarce and conflicting. Edi-Osagie et al suggested that a favorable outcome might be expected with enhancing uterine perfusion in unexplained infertility cases. $^{25}$ Treatment with sildenafil citrate improved endometrial thickness, increased pregnancy rate as well as opposing the endometrial adverse outcomes associated with clomiphene treatment. ${ }^{15,26,27}$ Isosorbide mononitrite significantly improved uterine artery and sub-endometrial perfusion. ${ }^{14} \mathrm{~A}$ favorable outcome was reported with oral L-arginine in poor responders undergoing IVF. ${ }^{28}$ On the other hand, in a randomized controlled trial, Battaglia et al reported that L-arginine adversely affected pregnancy rate in women undergoing IVF. ${ }^{29}$ Moreover, in cases with recurrent miscarriage, sildenafil citrate, isosorbide mononitrite and $\mathrm{N}$-acetyl cysteine improved uterine artery Doppler indices. ${ }^{30-32}$

Gutarra-Vilchez et al published a Cochrane review investigating the effect of vasodilators on endometrial thickness and reported a beneficial effect for endometrial thickening but the authors concluded this effect is uncertain due to very low-quality evidence. ${ }^{33}$ It must be noted that no studies assessing the effect of nitroglycerin was included in that review.

Thin endometrium is suggested to have a detrimental effect on pregnancy rate. ${ }^{34}$ Although the best cutoff to predict pregnancy is still to be determined but previous studies reported a positive relation between pregnancy rate and endometrial thickness. ${ }^{6}$ Eftekhar et al found the highest pregnancy rate with endometrial thickness between 8 and $11 \mathrm{~mm} .{ }^{35}$ Several reports concluded that maximizing endometrial thickness is recommended before embryo transfer in women undergoing assisted reproduction. ${ }^{36}$ Singh et al recommended postponing embryo transfer in in-vitro fertilization cycles when endometrial thickness is $7 \mathrm{~mm}$ or less. ${ }^{37}$ It should be emphasized that the majority of these studies reported endometrial thickness in stimulated cycles in women undergoing in vitro fertilization. In the current population, all groups demonstrated an endometrial thickness exceeding these cutoffs but significantly thicker endometrium was found in the fertile group compared to controls which remained significant after nitroglycerine treatment.

Biochemical pregnancy in the present study was comparable between nitroglycerine treated women and controls $(6.67 \%$ versus $3.33 \%$ respectively). This result should be cautiously interpreted due to the very low pregnancy rate in both groups which is not sufficient to detect such small effect size for this secondary outcome or to allow firm conclusion. In a Cochrane review, higher pregnancy rate was reported in women undergoing fertility treatment with vasodilators treatment (relative risk $=1.45$, 95\% confidence interval $=1.19-1.77$ ) although it did not significantly improve live birth rate (relative risk $=1.18$, $95 \%$ confidence interval $=0.83-1.69) .{ }^{33}$

The current population reported headache, blurring of vision and hypotension with nitroglycerin treatment but these adverse effects were comparable to controls as well as to the fertile group. In disagreement with our results, vasodilators therapy significantly increased rates of side effects compared to placebo or no treatment, ${ }^{33}$ but it is worth noting that this Cochrane review included studies assessing different vasodilator compounds and no studies evaluating nitroglycerine was included, this might explain the difference from the current results. 
The current study has the following limitations: first, we did not investigate whether the known tachyphylaxis to vascular effects of nitroglycerin might have impacted the vascular endometrial response; second, women were followed up for spontaneous pregnancy over a single cycle, which might not reflect the typical clinical scenario in management of these women; third, the effect of nitroglycerine on pregnancy rate could not be concluded from the current results due to the small sample size to assess this outcome.

\section{CONCLUSION}

In women with unexplained infertility, nitroglycerin significantly improved the sub-endometrial blood flow but did not affect the endometrial thickness. Doppler study of uterine and sub-endometrial blood flow may be considered in infertility workup for women with unexplained infertility and if impaired perfusion is detected, transdermal nitroglycerin seems a promising treatment in such cases. Further research is recommended to evaluate nitroglycerine for multiple consecutive cycles.

\section{Funding: No funding sources}

Conflict of interest: None declared

Ethical approval: The study was approved by the Institutional Ethics Committee- Faculty of Medicine Ain Shams University Research Ethics Committee (FMASU REC); 296/2016.

\section{REFERENCES}

1. American Society of Reproductive Medicine. Evidence-based treatments for couples with unexplained infertility: a guideline. Fertil Streril. 2020;113(2):305-22.

2. Kupesic S, Bekavac I, Bjelos D, Kurjak A. Assessment of endometrial receptivity by transvaginal color Doppler and three-dimensional power Doppler ultrasonography in patients undergoing in vitro fertilization procedures. J Ultrasound Med. 2001;20(2):125-34.

3. Elnaggar A, Farag AH, Gaber M, Hafeez MA, Ali MS, Atef AM. AlphaVBeta3 Integrin expression within uterine endometrium in unexplained infertility: a prospective cohort study. BMC Womens Health. 2017;17(1):90.

4. Craciunas L, Gallos I, Chu J, Bourne T, Quenby S, Brosens JJ, Coomarasamy A. Conventional and modern markers of endometrial receptivity: a systematic review and meta-analysis. Hum Reprod Update. 2019;25(2):202-23.

5. Kim A, Jung H, Choi WJ, Hong SN, Kim HY. Detection of endometrial and sub-endometrial vasculature on the day of embryo transfer and prediction of pregnancy during fresh in vitro fertilization cycles. Taiwan J Obstet Gynecol. 2014;53(3):360-65.

6. Wang L, Shulan LV, Mao W, Pei M, Yang X. Assessment of endometrial receptivity during implantation window in women with unexplained infertility. Gynecol Endocrinol. 2020.

7. Kim A, Han JE, Yoon TK, Lyu SW, Seok HH, Won HJ. Relationship between endometrial and subendometrial blood flow measured by threedimensional power Doppler ultrasound and pregnancy after intrauterine insemination. Fertil Steril. 2010;94(2):747-52.

8. Zebitay AG, Tutumlu M, Verit FF, Ilhan GK, Gungor ES, Cetin $\mathrm{O}$ et al. A comparative analysis of arterial blood flow in unexplained infertility, tubal infertility and fertile groups. Gynecol Endocrinol. 2016;32(6):442-5.

9. Mörlin B, Hammarström M. Nitric oxide increases endocervical secretion at the ovulatory phase in the female. Acta Obstet Gynecol Scand. 2005;84(9):8836.

10. Dubey PK, Tripathi V, Singh RP, Saikumar G, Nath A, Pratheesh Gade $\mathrm{N}$ et al. Expression of nitric oxide synthase isoforms in different stages of buffalo (Bubalus bubalis) ovarian follicles: effect of nitric oxide on in vitro development of preantral follicle. Theriogenology. 2012;77(2):280-91.

11. Hefler LA, Gregg AR. Inducible and endothelial nitric oxide synthase: genetic background affects ovulation in mice. Fertil Steril. 2002;77(1):147-51.

12. Zamberlam G, Sahmi F, Price CA. Nitric oxide synthase activity is critical for the preovulatory epidermal growth factor-like cascade induced by luteinizing hormone in bovine granulosa cells. Free Radic Biol Med. 2014;74:237-44.

13. Van Buren GA, Yang DS, Clark KE. Estrogeninduced uterine vasodilatation is antagonized by Lnitroarginine methyl ester, an inhibitor of nitric oxide synthesis. Am J Obstet Gynecol. 1992;167(3):828-33.

14. Abdel Razik M, El-Berry S, El-Nezamy A, Saad A, Abdel Wahab A. Nitric oxide donors increase the pregnancy rate in patients with unexplained infertility undergoing clomiphene citrate stimulation and intrauterine insemination: a randomized controlled pilot study. Gynecol Endocrinol. 2016.

15. Fetih AN, Habib DM, Abdelaal II, Hussein M, Fetih GN, Othman ER. Adding sildenafil vaginal gel to clomiphene citrate in infertile women with prior clomiphene citrate failure due to thin endometrium: a prospective self-controlled clinical trial. Facts Views Vis Obgyn. 2017;9(1):21-7.

16. El-Mazny A, Abou-Salem N, ElShenoufy H. Doppler study of uterine hemodynamics in women with unexplained infertility. European J Obstet Gynecol Reprod Biol. 2013;171(2013):84-7.

17. El-Zenneni H, Moustafa R, Abdel-Hafeez M, ElSalally H, Abdel-Kader A, Elnaggar A. Assessment of uterine, subendometrial blood flows and endometrial gland vascular endothelial growth factor (EG-VEGF) in women with unexplained infertility. Middle East Fertil Soc J. 2015;20:119-26.

18. Uysal S, Ozbay EP, Ekinci T, Aksüt H, Karasu S, Işı $\mathrm{AZ}$ et al. Endometrial spiral artery Doppler parameters in unexplained infertility patients: is 
endometrial perfusion an important factor in the etiopathogenesis? J Turk Ger Gynecol Assoc. 2012;13(3):169-71.

19. Chen M, He Y, Zhang P, Geng Q, Liu Q, Kong L et al. comparison of uterine receptivity between fertile and unexplained infertile women by assessment of endometrial and subendometrial perfusion using contrast-enhanced ultrasound: which index is better peak intensity or area under the curve? Ultrasound in Med Biol. 2016;42(3):654-63.

20. Hashad A, Ibrahim I, Etman M, Elkholy H. A Study of Endometrial Perfusion in Unexplained Infertility. The Egyptian J Hospital Med. 2018;72(6):4673-80.

21. Ibrahim AM, El-Mandooh M, Fathy H, Alhariri HA. Ovarian and Uterine Blood Flow Indices in Patients with Unexplained Infertility Undergoing ICSI and their Relation to Clinical Pregnancy Rate. EBWHJ. 2020;10(3):188-200.

22. Schild RL, Holthanus S, d'Alquen J, Fimmers R, Dorn C, van der Ven H et al. Quantitative assessment of subendometrial blood flow by three-dimensionalultrasound is an important predictive factor of implantation in an in-vitro fertilization programme. Hum Reprod. 2000;15(1):89-94.

23. Ohl J, Lefèbvre-Maunoury C, Wittrmer C, Nisand G, Laurent M, Hoffmann P. nitric oxide donors for patients undergoing IVF. A prospective, double-blind, randomized, placebo-controlled trial. Human Reprod. 2002;17(10):2615-20.

24. Farzi F, Mehrafza M, Mirmansouri A, Oudi M, Hoseeini A. Administration of NTG before embryo transfer does not increase pregnancy rate. IJRM. 2005;3(2):95-100.

25. Edi-Osagie E, Seif M, Aplin J, Jones C, Wilson G, Lieberman B. Characterizing the endometrium in unexplained and tubal factor infertility: a multiparametric investigation. Fertil Steril. 2004;82:1379-89.

26. Aboelroose A, Ibrahim A, Madny E, Elmazzahy A, Taha O. A randomized clinical trial of sildenafil plus clomiphene citrate to improve the success rate of ovulation induction in patients with unexplained infertility. Int J Gynecol Obstet. 2020;150:72-6.

27. Hamid AMA, Elbiaa AMA Saadoun RA, Rateb A, Madkour WAI. Effect of Adding Sildenafil to Clomiphene Citrate versus Clomiphene Citrate alone on Endometrium in Unexplained Infertility: CrossSectional, Non-Randomized Study. Obstet Gynecol Int J. 2017;7(2):00243.

28. Battaglia C, Salvatori M, Maxia N, Petraglia F, Facchinetti F, Volpe A. Adjuvant L-arginine treatment for in-vitro fertilization in poor responder patients. Hum Reprod. 1999;14(7):1690-7.

29. Battaglia C, Regnani G, Marsella T, Facchinetti F, Volpe A, Venturoli $\mathrm{S}$ et al. Adjuvant L-arginine treatment in controlled ovarian hyperstimulation: a double-blind, randomized study. Hum Reprod. 2002;17(3):659-65.

30. Bahaa HA. Efficacy of sildenafil citrate in women with unexplained recurrent miscarriage preconceptional and during 1st trimester of pregnancy. EBWHJ. 2018;8(1):138-44.

31. Abdel Razik M, El-Berry S, Mostafa A. The effects of nitric oxide donors on uterine artery and subendometrial blood flow in patients with unexplained recurrent abortion. J Reprod Infertil. 2014;15(3):1426.

32. Amin AF, Shaaban OM, Bediway MA. N-acetyl cysteine for treatment of recurrent unexplained pregnancy loss. Reprod Biomed Online. 2008;17(5):722-6.

33. Gutarra-Vilchez RB, Bonfill Cosp X, Glujovsky D, Viteri-García A, Runzer-Colmenares FM, MartinezZapata MJ. Vasodilators for women undergoing fertility treatment. Cochrane Database Systematic Reviews. 2018;10;CD010001.

34. Fang R, Cai L, Xiong F, Chen J, Yang W, Zhao X. The effect of endometrial thickness on the day of hCG administration on pregnancy outcome in the first fresh IVF/ICSI cycle. Gynecol Endocrinol. 2016;32(6):473-6.

35. Eftekhar M, Mehrjardi S, Molaei B, Taheri F, Mangoli E. The correlation between endometrial thickness and pregnancy outcomes in fresh ART cycles with different age groups: a retrospective study. Middle East Fertil Soc J. 2019;24:10.

36. He L, Zhanga Z, Li H, Li Y, Long L, He W. Correlation between endometrial thickness and perinatal outcome for pregnancies achieved through assisted reproduction technology. J Perinat Med. 2019; aop.

37. Singh N, Bahadur A, Mittal S, Malhotra N, Bhatt A. Predictive value of endometrial thickness, pattern and sub-endometrial blood flows on the day of hCG by 2D Doppler in in-vitro fertilization cycles: A prospective clinical study from a tertiary care unit. J Hum Reprod Sci. 2011;4(1):29-33.

Cite this article as: Hafeez MAA, Kortam AMF, Youssef AMA, Reda A, Abdelrahman RM. Effect of nitric oxide donors on uterine and sub-endometrial blood flow in patients with unexplained infertility: a randomized controlled trial. Int J Reprod Contracept Obstet Gynecol 2021;10:2178-84. 